\title{
Przegląd narzędzi diagnostycznych i metod pomiaru zespołu stresu pourazowego (Posttraumatic Stress Disorder, PTSD) z możliwością wykorzystania wśród ratowników medycznych
}

Overview of diagnostic tools and Posttraumatic Stress Disorder (PTSD) measurement methods with the possibility of use among paramedics

\section{Justyna Kosydar-Bochenek' ${ }^{1}$, Bogumił Lewandowski ${ }^{1,2}$, Dorota Ozga ${ }^{1}$, Krystyna Woźniak ${ }^{1}$}

'Katedra Ratownictwa Medycznego Wydziału Medycznego Uniwersytetu Rzeszowskiego ${ }^{2}$ Kliniczny Oddział Chirurgii Szczękowo-Twarzowej Wojewódzkiego Szpitala Specjalistycznego w Rzeszowie

CORRESPONDING AUTHOR/AUTOR DO KORESPONDENCJ: Justyna Kosydar-Bochenek

Wydział Medyczny, Uniwersytet Rzeszowski

Katedra Ratownictwa Medycznego

ul. Pigonia 6, 35-310 Rzeszów

tel. (17) 8721430

e-mail: justynakosydar@wp.pl

STRESZCZENIE

Słowa kluczowe:

ABSTRACT

Key words:
PRZEGLAD NARZEZDZ DIAGNOSTYCZNYCH I MEIOD POMIARU ZESPORU STRESU POURAZOWEGO (POSTTRAUMATIC STRESS DISORDER, PISD) Z MOŻLIWOŚCIA WYKORZYSTANIA WŚRÓD RAIOWNIKÓW MEDYCZNYCH

Zawód ratownika medycznego wiąże się z ciągłym kontaktem z traumatycznymi wydarzeniami - wypadkami, katastrofami, kataklizmami, aktami przemocy itp. Konsekwencją częstego i długotrwałego narażenia na zdarzenia traumatyczne wśród ratowników medycznych są zaburzenia po stresie traumatycznym, określane także jako zespół stresu pourazowego lub zaburzenie stresowe pourazowe (z ang. Posttraumatic Stress Disorder - PTSD). Są to przewlekłe zaburzenia poznawcze, emocjonalne, behawioralne oraz somatyczne w wyniku przedłużonej reakcji na stresujące wydarzenia lub sytuacje o charakterze zagrażającym życiu i/lub bezpieczeństwu. Metody stosowane do diagnozowania PTSD można podzielić na dwie grupy: ustrukturyzowane wywiady i kwestionariusze do samooceny (self-rating scales). Badacz powinien wybrać najlepszą metodę nie tylko ze względu na procedurę prowadzonych badań, ale również jej merytoryczne i psychometryczne parametry. Niniejszy artykuł przedstawia przegląd polskich i zagranicznych sposobów pomiaru PTSD, które mogą znaleźć zastosowanie w badaniach prowadzonych w grupie ratowników medycznych.

zespół stresu pourazowego, stres traumatyczny, ratownik medyczny, ustrukturyzowany wywiad, kwestionariusz do samooceny

\section{OVERVIEW OF DIAGNOSTIC TOOLS AND POSTTRAUMATIC STRESS DISORDER (PTSD)} MEASUREMENT METHODS WIHH THE POSSIBILIV OF USE AMONG PARAMEDICS

The profession of a paramedic involves a constant contact with traumatic events - road accidents, disasters, acts of violence and so on. As a consequence of such frequent and long-lasting exposure to traumatic events, paramedics are prone to developing PTSD (Posttraumatic Stress Disorder). This is a chronic disorder impacting cognitive, emotional, behavioral and somatic experiences. As a result of a prolonged exposure to stressful events, such condition can be life threatening. There are two ways of diagnosing PTSD: structured interviews and self-rating questionnaires (self-rating scales). The researcher should choose the best method possible relying not only on its procedure. In addition, merit based factors and psychometric parameters should be taken into consideration. The present article provides an overview of both Polish as well as foreign PTSD assessment methods, which could be incorporated into the research conducted in a group of paramedics.

Posttraumatic Stress Disorder (PTSD), traumatic stress, paramedics, structured interview, self-rating scales 


\section{WPROWADZENIE}

Ratownicy medyczni to grupa zawodowa szczególnie narażona na sytuacje stresujące, traumatyczne i skrajnie obciążające. W codziennej praktyce zawodowej spotykają się z ludzkim cierpieniem i tragediami, dlatego często dochodzi u nich do kumulowania się stresujących doświadczeń, które w wyniku tzw. „efektu dawki” może skutkować wytworzeniem się symptomów zaburzenia stresowego pourazowego [1].

Posttraumatic Stress Disorder (PTSD) zostało wprowadzone do systemu klasyfikacji i diagnozy zaburzeń psychicznych (Diagnostic and Statistical Manual of Mental Disorders, DSM) w 1980 roku. W polskim piśmiennictwie reakcję tę określa się najczęściej jako zespół stresu pourazowego, zaburzenie stresowe pourazowe lub zaburzenie po stresie traumatycznym/urazowym $[2,3,4]$.

PTSD może powstać na skutek zdarzenia, które osoba przeżyła osobiście lub była świadkiem, a z którym wiązało się rzeczywiste lub subiektywnie odczuwane zagrożenie życia lub fizycznej integralności $[5,6,7]$. Według najnowszej wersji klasyfikacji DSM (DSM-5, 2013) objawy zaburzenia stresowego pourazowego mogą pojawić się również, jeżeli traumatyczne wydarzenie rozumiane jako śmierć i zagrożenie życia związane z przemocą lub nagłym wypadkiem dotknęło bliskiego krewnego lub przyjaciela oraz w przypadku, gdy osoba doświadcza powtarzającego się lub skrajnie nasilonego wydarzenia, co ma szczególne znaczenie w przypadku ratowników medycznych i innych pracowników służb ratowniczych [8].

U osób, które doświadczyły zdarzenia traumatycznego, wystąpić mogą trzy główne grupy objawów:

- ponowne przeżywanie traumy,

- unikanie bodźców (m.in. rzeczy, ludzi, miejsc, sytuacji), które przypominają o traumie,

- nadmierna pobudliwość $[6,8]$.

Charakterystykę poszczególnych grup objawów zawiera tabela 1 .

Objawy zespołu stresu pourazowego często występują bezpośrednio po zdarzeniach traumatycznych, ale w przypadku większości osób, które doznają traumy, ich często- tliwość i nasilenie zmniejszają się naturalnie w procesie dochodzenia do siebie. Jednak u części osób objawy PTSD utrzymują się, a zaburzenie stresowe pourazowe nabiera charakteru przewlekłego, co utrudnia codzienne funkcjonowanie w życiu zawodowym i osobistym $[9,10]$.

\section{METODY POMIARU PTSD}

Od momentu wprowadzenia po raz pierwszy pojęcia PTSD jako jednostki chorobowej do systemu klasyfikacji zaburzeń psychicznych (DSM-III, 1980) opracowano wiele technik pozwalających je diagnozować [11]. Umożliwia to badaczom dobór takiej metody, która jest najlepiej dostosowana do zaplanowanej procedury badania. Dla przykładu, jeśli badanymi są ratownicy medyczni szukający pomocy w przychodni zdrowia psychicznego, badacz może wybrać jedną z technik, która ma postać wystandaryzowanego wywiadu umożliwiającego postawienie diagnozy. Jeżeli prowadzone są badania na licznych grupach, np. populacji ratowników medycznych w danym województwie, wówczas badacz może wybrać kwestionariusz, który umożliwi osobom badanym dokonanie samooceny, co z kolei pozwoli na ocenę natężenia symptomów i rozpoznanie PTSD.

Wielość metod stwarza jednak pewną niedogodność, która polega na tym, że badacz powinien dobrać najlepszą metodę nie tylko ze względu na procedurę prowadzonych badań, ale również ze względu na jej merytoryczne i psychometryczne parametry. Musi zatem dokonać oceny tych metod. Watson i in. proponują, aby podczas tej oceny rozważyć następujące kwestie:

- czy treść pytań odnosi się do kryteriów zawartych w DSM?

- czy wybrana metoda cechuje się wystarczającą trafnością i rzetelnością?

- czy metoda umożliwia dokonanie dychotomicznego rozróżnienia występowania lub braku PTSD oraz spełnienie każdego kryterium zaburzenia przedstawionego w DSM?

Tab. 1. Objawy zespołu stresu pourazowego PTSD

\begin{tabular}{|c|c|c|}
\hline Intruzja/ponowne przeżywanie & Unikanie & Nadmierna pobudliwość \\
\hline $\begin{array}{l}\text { - uporczywe i natrętne wspomnienia zdarzenia } \\
\text { obejmujące wyobrażenia, myśli i spostrzeganie, } \\
\text { • powracające dystresujące sny dotyczące zdarzenia, } \\
\text { - fizyczne bądź psychiczne odczuwanie, jak gdyby } \\
\text { zdarzenie urazowe powracało (obejmuje poczucie } \\
\text { ponownego doświadczania, iluzje, halucynacje i } \\
\text { epizody reminiscencji dysocjacyjnych/ obsesyjnych), } \\
\text { • intensywny dystres psychologiczny wskutek } \\
\text { ekspozycji na coś, co wewnętrznie lub zewnętrznie } \\
\text { symbolizuje lub przypomina jakiś aspekt zdarzenia } \\
\text { urazowego, } \\
\text { - fizjologiczna reaktywność przy ekspozycji na } \\
\text { wewnętrzne i zewnętrzne wpływy symbolizujące lub } \\
\text { przypominające jakiś aspekt zdarzenia urazowego }\end{array}$ & $\begin{array}{l}\text { - unikanie myśli, uczuć i rozmów związanych z urazem, } \\
\text { • unikanie aktywności, miejsc } \\
\text { i ludzi wywołujących wspomnienia związane z } \\
\text { urazem, } \\
\text { • niemożność przypomnienia sobie ważnych aspektów } \\
\text { urazu, } \\
\text { • „anestezja emocjonalna”, } \\
\text { - znacząco ograniczone zainteresowania lub } \\
\text { uczestnictwo w ważnych aktywnościach, } \\
\text { - poczucie odrzucenia przez innych i zrażenie się do } \\
\text { ludzi, } \\
\text { • zawężone odczuwanie afektu (np. niemożność } \\
\text { przeżywania miłości), } \\
\text { • poczucie braku perspektyw na przyszłość (np. ktoś } \\
\text { nie spodziewa się kariery, małżeństwa, dzieci czy } \\
\text { przeciętnie długiego życia). }\end{array}$ & $\begin{array}{l}\text { - trudności z zasypianiem lub snem, } \\
\text { • drażliwość lub wybuchy gniewu, } \\
\text { • trudności z koncentracją, } \\
\text { - wzmożona czujność, } \\
\text { - nadmiernie silna reakcja na niespodziewane } \\
\text { bodźce. }\end{array}$ \\
\hline
\end{tabular}


- czy metoda umożliwia pomiar nasilenia i częstości występowania zarówno PTSD, jak i poszczególnych symptomów?

- czy metoda jest na tyle łatwa, że nie musi jej stosować specjalista? [4].

Postuluje się wybór takiej metody, w przypadku której można odpowiedzieć twierdząco na wszystkie wymienione pytania.

Metody stosowane do diagnozowania PTSD można podzielić na dwie zasadnicze grupy: ustrukturyzowane wywiady i kwestionariusze do samooceny (self-rating scales) [2]. Niektórzy badacze wyróżniają trzy kategorie instrumentów badawczych PTSD: ustrukturyzowane wywiady, skale inwentarzowe i kwestionariusze [12].

\section{NARZĘDZIA POMIARU W FORMIE WYWIADU KLINICZNEGO}

Do narzędzi pomiaru w formie wywiadu klinicznego, które mogą mieć zastosowanie w grupie ratowników medycznych zaliczyć można:

- strukturalizowany wywiad kliniczny dla DSM-IV (SCID-I, Structured Clinical Interview for DSM-IV),

- skalę PTSD w formie wywiadu klinicznego (CAPS, Clinician Administered PTSD Scale),

- wywiad dla zaburzenia stresowego pourazowego (PTSD-I),

- wywiad skali symptomów PTSD (PSS-I, PTSD Symptom Scale-Interview),

- schemat wywiadu diagnostycznego (DIS, Diagnostic Interview Schedule).

Najczęściej używanymi narzędziami są: Diagnostic Interview Schedule (DIS) i Structured Clinical Interview for DSM-IV (SCID) - moduł do oceny PTSD. DIS może być używany przez przeszkolonego niespecjalistę, co stanowi zaletę przy badaniu dużych grup ludzi. Właściwości psychometryczne tej metody były jednak obiektem krytyki. Lepiej oceniana była druga metoda, którą traktowano jako najlepszą w badaniach klinicznych nawet wtedy, gdy nie oszacowano jeszcze jej parametrów psychometrycznych. Badania przeprowadzone nad tą metodą wykazały wysoką zgodność ocen między sędziami oraz wysoką czułość (proporcja trafnych rozpoznań przypadków z PTSD). W obu metodach, DIS i SCID, każdy symptom PTSD rozpatruje się oddzielnie, ale ocenia się tylko po względem nasilenia; nie ocenia się częstości ich występowania [12].

Metody spełniające wymóg obu ocen (nasilenie i częstość) to Structured Interview dla PTSD (SI-PTSD) i Clinician Admininistred PTSD Scale (CAPS), które cechują się bardzo dobrymi parametrami psychometrycznymi [4].

Kolejnym ustrukturyzowanym wywiadem jest PTSDInterview (PTSD-I) opracowany przez Watsona i współpracowników. Wywiad PTSD składa się z trzech części. Pierwsza zawiera pytanie: czy badany doświadczył zdarzenia traumatycznego, następnie pytania związane $\mathrm{z}$ charakterystyką, krótkim opisem tego zdarzenia. Druga część to siedemnaście pytań dotyczących częstości, intensywności objawów PTSD (nawracanie, unikanie, pobudzenie).
Trzecia część to pytania dotyczące częstotliwości i okresu występowania symptomów [12].

Tab. 2. Metody rozpoznawania PTSD do zastosowania w grupie ratowników medycznych

\begin{tabular}{|c|c|}
\hline Ustrukturyzowany wywiad kliniczny & Metody oparte na samoocenie \\
\hline \begin{tabular}{|l} 
- strukturalizowany wywiad kliniczny \\
dla DSM-IV (SCID-I, Structured Clinical \\
Interview for DSM-IV), \\
- wywiad skali symptomów PTSD \\
(PSS-I, PTSD Symptom Scale- \\
Interview), \\
- skala PTSD w formie wywiadu \\
klinicznego (CAPS, Clinician \\
Administered PISD Scale), \\
- schemat wywiadu diagnostycznego \\
(DIS, Diagnostic Interview Schedule), \\
- wywiad dla zaburzenia stresowego \\
pourazowego (PISD-I, Posttraumatic \\
Stress Disorder Index).
\end{tabular} & $\begin{array}{l}\text { - cywilna wersja skali Mississippi (MSC, } \\
\text { Mississippi Scale for Civilian Related } \\
\text { PTSD), } \\
\text { - pourazowa skala diagnostyczna (PTDS, } \\
\text { Posttraumatic Distress Syndrome), } \\
\text { - skala urazu Davidsona (DTS, Davidson } \\
\text { Trauma Scale), } \\
\text { - Skala Wpływu Zdarzeń (IES, Impact of } \\
\text { Event Scale) } \\
\text { i wersja zrewidowana, Zrewidowana } \\
\text { Skala Wpływu Zdarzeń (IES-R, Impact } \\
\text { of Event Scale-Revised), } \\
\text { - kwestionariusz do pomiaru zaburzenia } \\
\text { po stresie traumatycznym (K-PTSD), } \\
\text { Questionnaire for the Measurement of } \\
\text { Posttraumatic Stress Disorder, } \\
\text { - kwestionariusz do pomiaru zaburzenia } \\
\text { po stresie traumatycznym wersja } \\
\text { czynnikowa (PTSD-C), } \\
\text { - Self-Rating Scale for PTSD (SRS-PTSD), } \\
\text { - PTSD-Checklist (PCL), w tym PCL-C } \\
\text { (civilian), PCL-S (specific traumatic } \\
\text { event). }\end{array}$ \\
\hline
\end{tabular}

Źródło: na podstawie przeglądu piśmiennictwa

\section{NARZĘDZIA POMIARU OPARTE} NA SAMOOPISIE

Oprócz metod wykorzystujących wywiad do diagnozowania PTSD często stosuje się kwestionariusze samooceny. Narzędziami pomiaru opartymi na samoopisie, które mogą być wykorzystane w badaniach prowadzonych w grupie ratowników medycznych są:

- cywilna wersja skali Mississippi (MSC, Mississippi Scale for Civilian Related PTSD),

- pourazowa skala diagnostyczna (PTDS, Posttraumatic Distress Syndrome),

- skala urazu Davidsona (DTS, Davidson Trauma Scale),

- Skala Wpływu Zdarzeń (IES, Impact of Event Scale) i wersja zrewidowana, Zrewidowana Skala Wpływu Zdarzeń (IES-R, Impact of Event Scale-Revised),

- kwestionariusz do pomiaru zaburzenia po stresie traumatycznym (K-PTSD),

- kwestionariusz do pomiaru zaburzenia po stresie traumatycznym - wersja czynnikowa (PTSD-C),

- Self-Rating Scale for PTSD (SRS-PTSD),

- PTSD-Checklist (PCL) i jej wersje: PCL-C (civilian), PCL-S (specific traumatic event).

Jednym z bardziej znanych narzędzi służących do pomiaru PTSD jest skala wpływu zdarzeń (IES, Impact of Event Scale) [13]. Narzędzie powstało na podstawie obserwacji osób ujawniających objawy stresu pourazowego. Skala IES składa się z 15 twierdzeń. Uważa się ją za rzetelne i trafne narzędzie pomiaru, chociaż posiada dwa istotne mankamenty. Pierwszy dotyczy stosowania zarówno 4-, jak i 5-stopniowego systemu oceny, co utrud- 
nia porównywanie wyników. Drugi wiąże się z pomiarem tylko dwóch wymiarów składających się na obraz PTSD, czyli intruzji i unikania. W związku z tym skala IES często stosowana jest wraz z innymi narzędziami, np. GHQ Goldberga czy SCL-90 Derogatisa, uzupełniającymi pomiar trzeciego elementu PTSD związanego z pobudzeniem psychofizjologicznym. W Polsce badania przy użyciu skali IES prowadziła Lis-Turlejska [3,14,15, 16], potwierdzając jej dużą przydatność w praktyce.

Z powyższych powodów przyjęto zmodyfikowaną przez Weissa i Marmara skalę IES, która uwzględnia trzy wymiary PTSD. Zrewidowana Skala Wpływu Zdarzeń (IES-R, Impact of Event Scale-Revised) służy do ustalenia aktualnego, subiektywnego poczucia dyskomfortu związanego ze stresującymi wydarzeniami. Skala opisuje trzy wymiary PTSD: intruzję, wyrażającą powracające obrazy, sny, myśli lub wrażenia percepcyjne związane $\mathrm{z}$ traumą; pobudzenie, charakteryzujące się wzmożoną czujnością, lękiem, zniecierpliwieniem, trudnościami w koncentracji uwagi, oraz unikanie, przejawiające się w wysiłku pozbycia się myśli, emocji lub rozmów związanych z traumą [17]. Skala IES-R składa się z 22 twierdzeń, które opisują objawy odczuwanego stresu w ciągu ostatnich 7 dni w związku z doświadczonym zdarzeniem traumatycznym. Oceny dokonuje się na 5-stopniowej skali typu Likerta (0-4). Polski przekład IES-R został dokonany zgodnie z przyjętymi zasadami adaptacji transkulturowej przez Juczyńskiego i Ogińską-Bulik [17].

Kolejnym narzędziem do pomiaru PTSD jest kwestionariusz zespołu stresu pourazowego Mississippi, którego pytania odnoszą się do objawów PTSD wymienionych w DSM III-R oraz depresyjności, tendencji samobójczych i poczucia winy $[18,19]$. Pierwsza skala opracowana została w celu przeprowadzenia badania wśród kombatantów i weteranów wojennych - Mississippi Scale for Combat-Related PTSD i zawierała 35 pytań. W badaniach wśród ratowników medycznych wykorzystuje się jej wersję cywilną - Civilian Version Mississippi PTSD Scale. Skalę Mississippi w wersji cywilnej do warunków polskich zaadaptowała w 2001 roku M. Lis-Turlejska i A. Łuszczyńska-Cieślak [18].

W Instytucie Medycyny Pracy w Łodzi, wykorzystując ustrukturyzowany wywiad (PTSD-I) Watsona i wsp. opracowano kwestionariusz do pomiaru zaburzenia po stresie traumatycznym (K-PTSD) [20]. Polska wersja składa się z 17 pytań dotyczących częstości i/lub intensywności trzech objawów charakterystycznych dla PTSD. Nasilenie objawów badani oceniają według siedmiopunktowej skali. Skala zawiera także pytania dodatkowe o wystąpienie zdarzenia traumatycznego, jego charakterystykę, czas występowania i trwania. Kwestionariusz to narzędzie samooceny, jednak jego stosowanie jest uciążliwe ze względu na czas konieczny na ustosunkowanie się do wszystkich pytań. Strelau i wsp. [21] opracowali kwestionariusz PTSD - wersja czynnikowa (PTSD-C) do rozpoznawania i ustalania kryteriów zespołu stresu pourazowego.

Niektóre skale diagnostyczne są w trakcie adaptacji kulturowej do warunków polskich. Self-Rating Scale for PTSD (SRS-PTSD) jest kwestionariuszem do pomiaru PTSD i został opracowany przez Carlier i wsp. w 1998 roku. Skala składa się z 17 pytań i odnosi się do objawów wymienionych w definicji PTSD w DSM-IV [12].

PTSD-Checklist (PCL) jest narzędziem opisu własnych zachowań składającym się z 17 pozycji odpowiadającym symptomom PTSD. PCL ma różne zastosowania kliniczne i badawcze, w tym badanie rozpowszechnienia PTSD, pomoc w ocenie diagnostycznej PTSD, monitorowanie zmian symptomów PTSD. Dostępne są trzy wersje tego narzędzia: wojskowa, cywilna i wersja dotycząca konkretnego wydarzenia traumatycznego [11].

Oprócz wymienionych dwóch grup metod do diagnozy PTSD: ustrukturyzowane wywiady i kwestionariusze do samooceny, J. Heitzman wyróżnia dodatkowo trzecią grupę narzędzi badawczych PTSD: kwestionariusze i inne narzędzia łączące metody inwentarza i samooceny. Autor wymienia tu m.in.: kwestionariusz PTSD Salomona (1987), wywiad PTSD Goldsteina (1987), kwestionariusz Carda (1983), kwestionariusz Foy (1984) [12].

\section{BADANIA NEUROPSYCHOLOGICZNE I METODY OBRAZOWE}

W celu potwierdzenia rozpoznania PTSD wykonuje się między innymi badania neuropsychologiczne, które wykazują m.in. gorsze niż w grupach kontrolnych wskaźniki poziomu kompetencji wzrokowo-konstrukcyjnych, a także niższe wyniki w podtestach badających natychmiastowe i odroczone przypominanie treści werbalnych, gorsze wyniki zadań wzrokowo-przestrzennych, jak również obniżenie wyników w próbach, które badają pamięć werbalną i wzrokowo-przestrzenną [22]. Wyniki testów neuropsychologicznych wskazują na to, że zaburzenia psychiczne towarzyszące objawom PTSD mogą nasilać zmiany deficytowe dotyczące sfery poznawczej [2].

Do wysokospecjalistycznych badań diagnozujących PTSD należą metody obrazowe, w których stwierdza się:

- zmniejszenie objętości hipokampa oraz lateralizację zmian (u osoby z pełnoobjawowym PTSD po kilku latach od doświadczenia sytuacji traumatycznej ubytek może sięgać 10-20\% wcześniejszej objętości),

- w badaniach przeprowadzanych metodami funkcjonalnymi: zwiększenie przepływu krwi w prawostronnych obszarach limbicznych i paralimbicznych w prawej korze wyspy oraz zmniejszenie regionalnego przepływu krwi po stronie lewej w obrębie struktur skroniowych i obszaru Broca [2].

Ogólnie można przyjąć, że u osób z rozwiniętym zespołem PTSD aktywność obszarów podkorowych dominuje nad aktywnością korową mózgu [22].

\section{WNIOSKI}

Ratownicy medyczni w czasie pełnienia obowiązków zawodowych często są uczestnikami lub świadkami zdarzeń, które mają cechy właściwe dla zdarzeń traumatycznych. Konsekwencją częstego i długotrwałego narażenia na takie zdarzenia mogą być zaburzenia po stresie traumatycznym [23]. Istotna jest zatem ochrona zdrowia psychicznego osób szczególnie narażonych na ryzyko 
wystąpienia u nich objawów zespołu stresu pourazowego. Działania te powinna jednak poprzedzić ocena częstości występowania, jak również nasilania objawów PTSD, a to umożliwić mogą odpowiednio dobrane narzędzia diagnostyczne.

\section{PIŚMIENNICTWO}

1. Wawrzynowicz H, Romańczukiewicz J. Zaburzenie po stresie traumatycznym tendencje badawcze. Pielęgniarstwo Polskie. 2005; 1(19): 73-78.

2. Holiczer A, Gałuszko M, Cubała WJ. Zaburzenie stresowe pourazowe - opis ewolucji koncepcji zaburzenia i podejść terapeutycznych. Psychiatria. 2007; 4(1): 25-32.

3. Lis-Turlejska M. Traumatyczne zdarzenia i ich skutki psychologiczne. Warszawa: Wyd. Instytutu Psychologii PAN; 2005.

4. Dudek B. Zaburzenia po stresie traumatycznym. Gdańsk: Gdańskie Wydawnictwo Psychologiczne GWP; 2003.

5. ICD-10. Międzynarodowa Statystyczna Klasyfikacja Chorób i Problemów Zdrowotnych. Rewizja dziesiąta. Klasyfikacja zaburzeń psychicznych i zaburzeń zachowania w ICD-10. Opisy kliniczne i wskazówki diagnostyczne. KrakówWarszawa: Uniwersyteckie Wydawnictwo Medyczne „Vesalius", Instytut Psychiatrii i Neurologii; 2000.

6. American Psychiatric Association. Diagnostic and statistical manual of mental disorders. Txt Revision. 4th ed. Washington; 2000.

7. Olasov Rothbaum B, Foa EB, Hembree EA. Odzyskaj życie po traumie. Przedłużona ekspozycja w terapii PTSD. Sopot: Gdańskie Wydawnictwo Psychologiczne GWP; 2013.

8. American Psychiatric Association: Diagnostic and Statistical Manual of Mental Disorders. 5th Edition: DSM-5; 2013.

9. Joseph S, Williams R. Understanding Posttraumatic Stress: Theory, Reflections, Context and Future. Behavioural and Cognitive Psychotherapy. 2005; 33(4): 423-441.
10. Radko J. Wtórny zespół stresu pourazowego w pracy strażaków i pracowników pogotowia ratunkowego - przegląd badań. Opuscula Sociologica. 2013; 3: 73-82.

11. Dąbkowska M. Rozpoznawanie zespołu stresu pourazowego. Neuropsychiatria i Neuropsychologia. 2008; 3 (2): 80-84.

12. Makara-Studzińska M, Partyka I, Ziemecki P. Zespół stresu pourazowego - rys historyczny, terminologia, metody pomiaru. Curr Probl Psychiatry. 2012; 13(2):109114.

13. Horowitz M, Wilner M, Alvarez W. Impact of Event Scale: A measure of subjective stress. Psychosom Med. 1979; 41: 209-218.

14. Lis-Turlejska M. Traumatyczny stres: koncepcje i badania. Warszawa: Wyd. Instytutu Psychologii PAN; 1998.

15. Lis-Turlejska M. Psychologiczne konsekwencje traumatycznego stresu współczesne kierunki badań. Nowiny Psychologiczne. 2000; 2.

16. Lis-Turlejska M. Stres traumatyczny: występowanie, następstwa, terapia. Warszawa: Wyd. Akademickie Żak; 2002.

17. Juczyński Z, Ogińska-Bulik N. Pomiar zaburzeń po stresie traumatycznym - polska wersja zrewidowanej skali wpływu zdarzeń. Psychiatria. 2009; 6(1):1-8.

18. Lis-Turlejska M, Łuszczyńska-Cieślak A. Adaptacja cywilnej wersji kwestionariusza zespołu stresu pourazowego: Misissippi PTSD Scale, Czas. Psychol. 2002; 7: 165-173.

19. Keane TM, Caddell JM, Taylor KL. Mississippi Scale for Combat-Related Posttraumatic Stress Disorder: three studies in reliability and validity. J Consult Clin Psychol. 1988; 5: 85-90.

20. Koniarek J, Dudek B, Szymczak B. Kwestionariusz do pomiaru zespołu zaburzeń po stresie urazowym (K-PTSD) - zastosowanie PTSD interview Ch. Watson i in w badaniach grupowych. Przegl. Psychol. 2000; 43: 205-216.

21. Strelau J, Zawadzki B, Oniszczenko W, Sobolewski A. Kwestionariusz PTSD - wersja czynnikowa (PTSD-C). Konstrukcja narzędzia do diagnozy głównych wymiarów zespołu stresu pourazowego. Przegl. Psychol. 2002; 45: 149-176.

22. Newport DJ, Nemeroff ChB. Neurobiology of Posttraumatic Stress Disorder, Curr. Opin. Neurobiol. 2000; 10: 211-218.

23. Hetherington A. Wsparcie psychologiczne w służbach ratowniczych. Gdańsk: Gdańskie Wydawnictwo Psychologiczne; 2004.

Praca przyjęta do druku: 22.10.2015

Praca zaakceptowana do druku: 18.01.2016 